\title{
The paintings of pathological anatomy by Sir Robert Carswell (1793-1857)
}

\author{
Arthur Hollman
}

Robert Carswell MD (fig 1) was a talented water-colour artist who created the finest and largest collections in Britain of illustrations of pathological conditions. He became a medical student in Glasgow in 1814 and it was there that he made his "first attempts to represent, by coloured delineations, the healthy and diseased appearances of the human body". ${ }^{1} \mathrm{He}$ did these while attending the lectures of James Jeffray (1759-1848) the professor of anatomy and physiology who encouraged him to develop his skills. His ability then came to the notice of Dr James Thomson (1765-1864), one of the foremost Edinburgh physicians of the time, who employed him to make illustrations of pathological specimens. For this purpose he went in 1822 to France where the supply of material was unrivalled and which was then in a period of unprecedented brilliance in pathological research. ${ }^{2}$ After two years in Paris and Lyons he returned to Scotland and by 1826 he had made an impres-

Correspondence to: Dr A Hollman, Department of Medicine, University College London Medical School, 5 University Street, London WC1E 6JJ.

Accepted for publication 11 April 1995

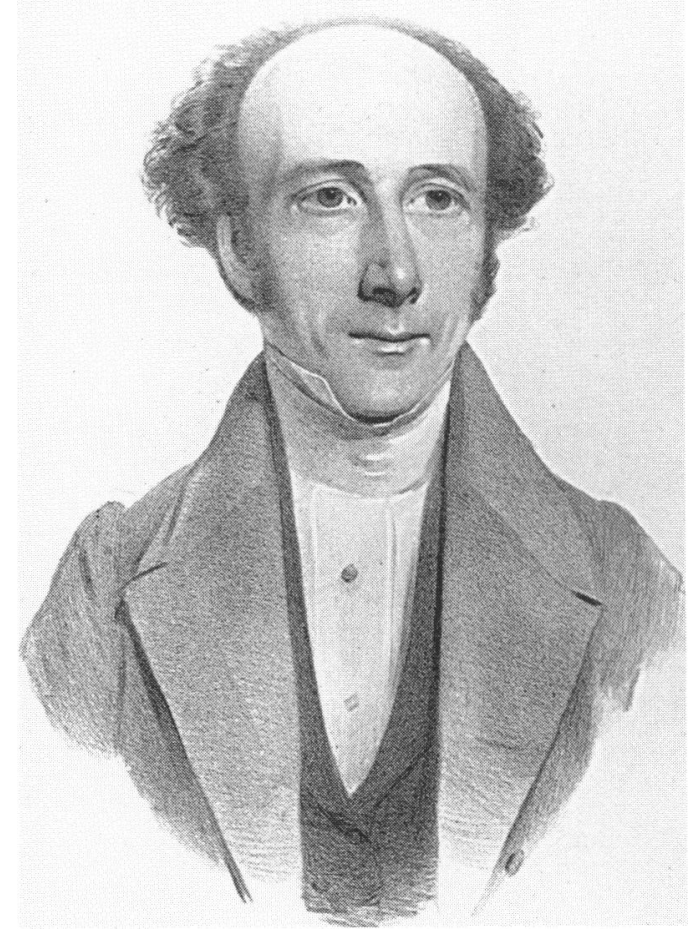

Figure 1 Portrait of Sir Robert Carswell. Artist and source of lithograph unknown. (Reproduced by kind permission of the President and Council of the Royal College of Surgeons of England). sively large collection of about 1200 illustrations, mostly in water-colour, for $\mathrm{Dr}$ Thomson's lectures on the practice of physic. He took the degree of MD at Aberdeen in 1826 and then returned to Paris to study under the celebrated physician Pierre C A Louis, and to continue his artistic work. While still there he was appointed in 1828 , at the age of 35 , as the first professor of pathological anatomy at University College London. The College Council then commissioned him to make a collection of illustrations for their museum and he stayed in Paris for another three years. By the time he returned in 1831 he had completed over 1000 pictures that were said at the time to be unequalled for their "artistic skill and accuracy of delineation and colouring". ${ }^{3}$ They were also among the last to be done before the study of morbid anatomy was revolutionised by the introduction of the microscope. It is this collection which is now described.

\section{The illustrations}

These are nearly all painted in water-colour with just a few in pen and ink. They range in size from $4 \mathrm{~cm} \times 4 \mathrm{~cm}$ to $45 \mathrm{~cm} \times 30 \mathrm{~cm}$. Most of them are of pathological specimens and some of these are shown in situ at postmortem examination. Others are of living patients, with pictures of the whole body as well as selected areas, such as the arm or face. The artistic quality is high and they are well preserved with little foxing of the paper. They are arranged in 17 sections and the number of paintings in each section is given in brackets: heart and blood vessels (98); breast and glandular system (42); larynx, tongue, thyroid (56); lungs, pleura, bronchi (146); brain, spinal cord (99); organs of locomotion (23); oesophagus, stomach (76); intestines, peritoneum (109); liver, spleen, pancreas (81); skin (60); urinary system (58); generative system: male (16); generative system: female (74); venereal disease (33); new formations (33); wounds and injuries (21); miscellaneous (9). The total of 1034 includes 24 paintings made in London after 1831.

Many of the paintings have a description of the pathology written in Carswell's own hand, and some also have the clinical history of the patient. These notes by Carswell were later 
copied into bound volumes. The entire collection is housed in the Department of Manuscripts and Rare Books in the library of University College London, and it is described in detail by Reckert ${ }^{4}$ in his book on Carswell.

\section{HEART AND CIRCULATION}

There is a good range of cardiac and vascular pathology in this section. There are several examples of pericardial disease. One is labelled tubercular pericarditis which at that time, 50 years before Robert Koch discovered the bacillus, would have been diagnosed from associated lesions. There is a fine painting of a large pericardial effusion with tremendous dilatation of the right atrium and superior vena cava, entitled "dropsy of the pericardium". Another is of "bone in pericardial adhesions", possibly a case of constrictive pericarditis. Rheumatic heart disease is of course well represented with examples of mitral, aortic, and tricuspid valve disease, but surprisingly there are no paintings of acute rheumatic endocarditis. Three paintings are labelled "warty excrescences" and look like infective endocarditis. Other instances of cardiac infection include an abcess at the apex of the heart and hydatid cysts in the wall of the left ventricle, though there are no gummata. Naturally, however, there are some striking examples of syphilitic aortic aneurysm, one with perforation of the oesophagus. There is a perforated aortic valve without endocarditis. The painting labelled "polypus of the heart" (A 5) is clearly a left atrial myxoma. Congenital heart disease is shown only six times, twice in adults, and this reflects the paucity of examples in children in the collection as a whole. Although Carswell attended two childrens' hospitals in Paris there are only 15 paintings from them. Was there a

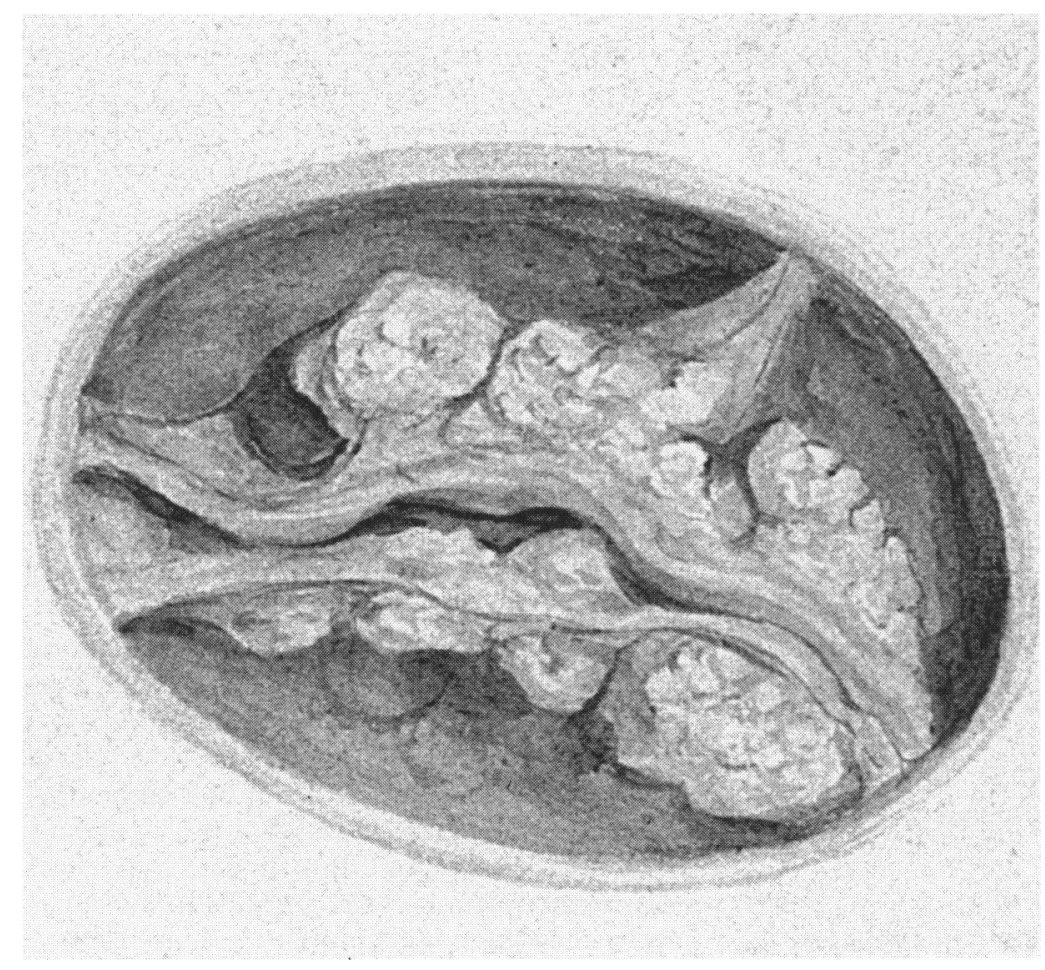

Figure 2 “Ossified semilunar valves". Painting A 532 in the Carswell collection. (Reproduced by permission of the Librarian, University College London).

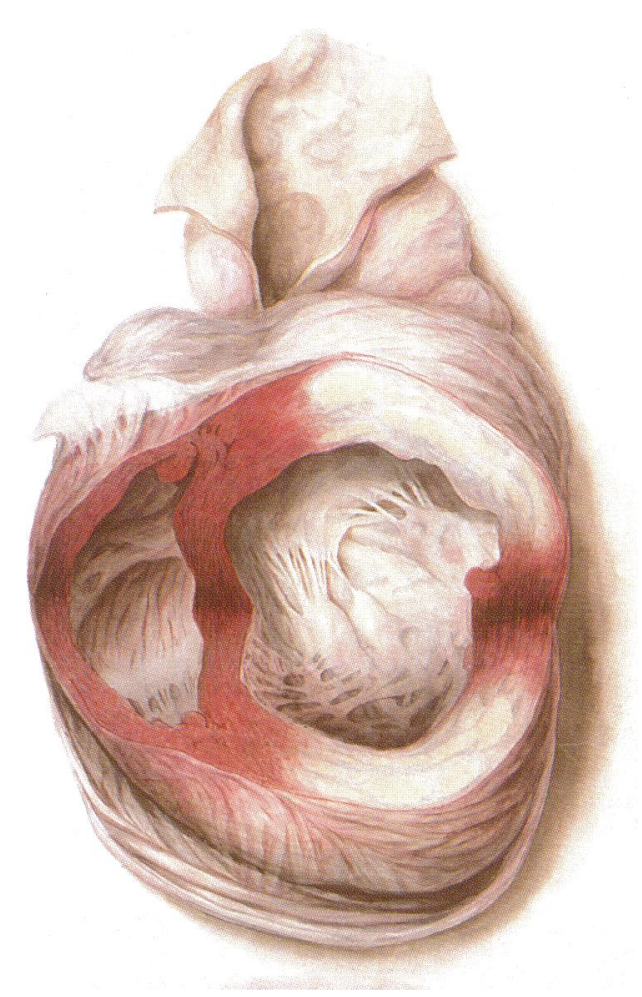

Figure 3 "Schirrhus or cancer of the heart". Painting $A$ 291 in the Carswell collection. (Reproduced by permission of the Librarian, University College London).

reluctance to do necropsies in this age group? An unusual example of the tetralogy of Fallot is called "partial obliteration of orifice of pulmonary artery" and there is a good illustration of pulmonary valve stenosis, and two paintings of young cyanosed patients. There is a fine demonstration in an adult of the arterial system in coarctation of the aorta, "contraction of aorta", and a specimen from a man of 50 (A 532) that shows calcific aortic stenosis in what may be a congenital bicuspid aortic valve (fig 2).

Coronary heart disease is represented by a specimen (A 704) labelled "atheroma of the coronary artery" which shows two thickened arteries opened longitudinally. A very interesting painting (A 291) is called "scirrhus or cancer of the heart. Thickening of internal membrane of the left ventricle. Adhesion of pericardium to the heart" (fig 3). It came from a man of 61 with right and left heart failure who had dyspnoea on effort, and also "praecordial oppression" which seems from the clinical notes not to have been cardiac pain. There is full thickness involvement of the anterior wall of the left ventricle, but because the ventricular mass has been divided transversly and the lower part turned down it looks at first like two separate lesions. This is probably a myocardial infarct, and if so it could be one of the earliest illustrations of this condition. Another illustration (A 919) which is described as "true aneurism of the heart" (fig 4) shows two sacs in the wall of the left ventricle communicating with the cavity. Perhaps these are congenital subvalvar aneurysms. He spells aneurysm with $\mathrm{i}$ not $\mathrm{y}$. There is also a painting showing a rupture of the left ventricle (A 917). 


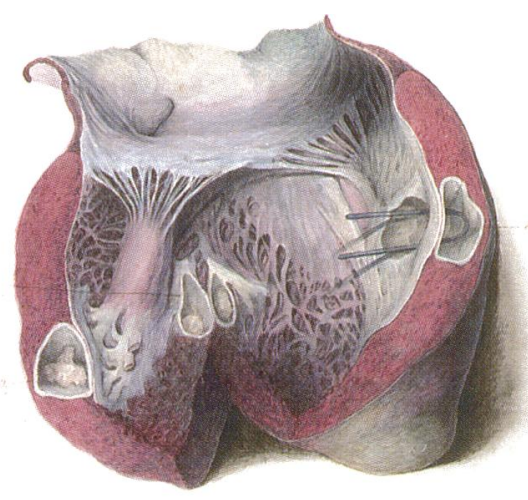

Figure 4 "True Aneurism of the Heart". Painting A 919 in the Carswell collection. The legend, written by Carswell, reads "True Aneurism of the Heart. The aneurismal sac lined by a membrane a, a,continuous with that of the ventricle. another smaller aneurism of a similar kind bboth contain portions of fibrine". (Reproduced by permission of the Librarian, University College London).

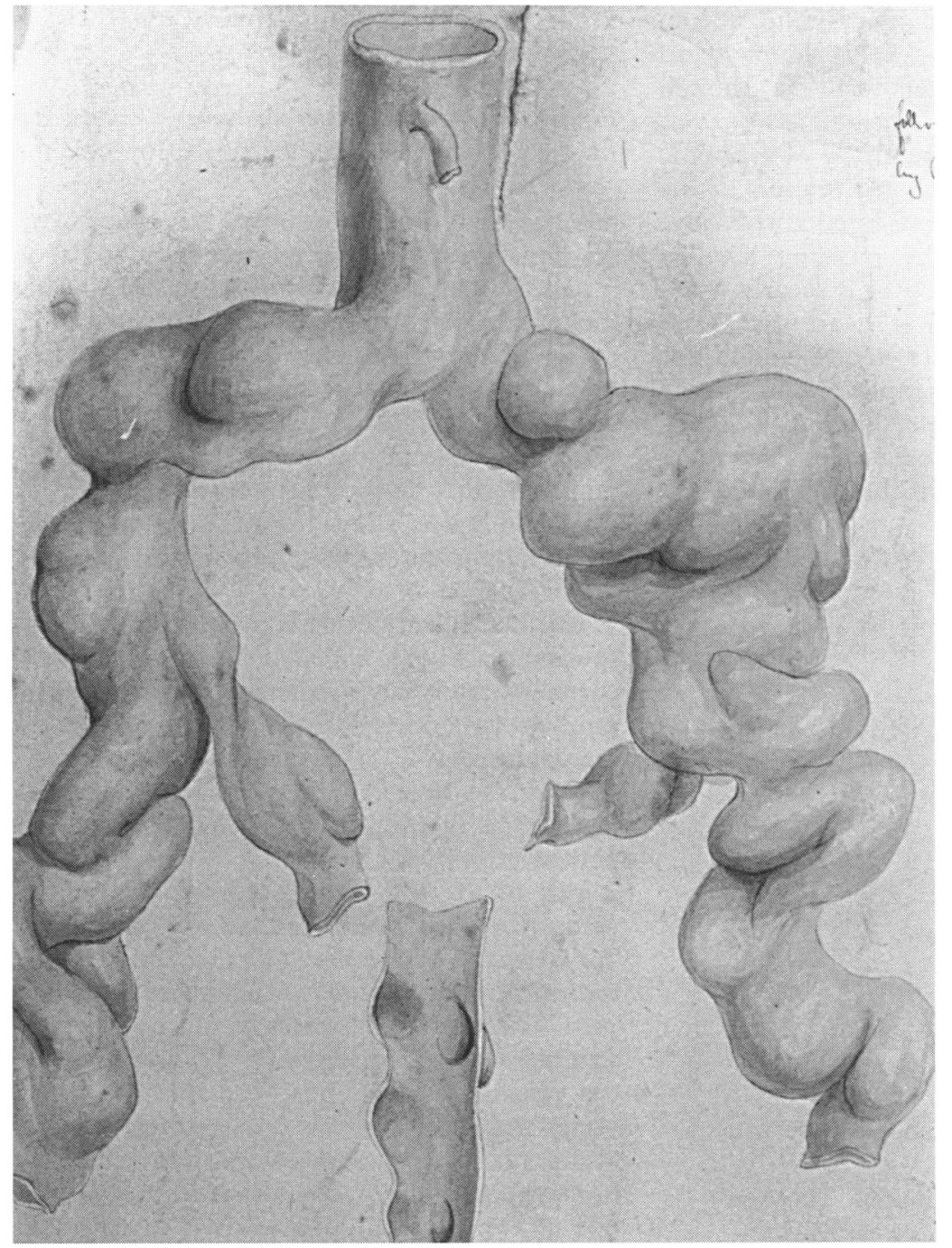

Figure 5 "Aneurysmal varix: varicose dilatation of arteries". Painting A 1032 in the Carswell collection. (Reproduced by permission of the Librarian, University College London).

A picture (A 15) labelled "aneursym of the ascending aorta" has been identified by Professor Tom Treasure (personal communication) as being a chronic dissection of the aorta (De Bakey type 2). The false lumen contains laminated clot and the base of the aorta has the characteristic appearance of a healed intimal tear. There is blood in the pericardium from, presumably, a terminal rupture. It is very likely that this is the first illustration of a chronic aortic dissection.

Atheroma of the ascending aorta and aneurysm of the abdominal aorta are well shown, as is arterial disease with pictures of calcified arteries and of gangrene of the legs. A really fascinating painting (A 1032), labelled "aneurysmal varix: varicose dilatation of arteries", shows numerous localised dilatations on the common iliac arteries and their branches (fig 5). There is no clinical description but it may be an example of the Ehlers-Danlos syndrome. Certainly it is a remarkable specimen. Disease of the veins includes obliteration of the inferior vena cava, iliac vein compression by cancer, venous thrombosis, and "pus and coagula in femoral vein".

\section{OTHER SYSTEMS OF THE BODY}

Carswell is famous for his illustrations in two systems other than the heart and blood vessels.

He was the first to depict the pathology in multiple sclerosis in a painting entitled "Circumscribed discolouration induration and transparency of the pons variolii and medulla spinalis" (D 445). Carswell's note on this case is as follows, "This remarkable appearance was observed in a patient who died at La Pitié after having remained a considerable time with paralysis. Mons. Louis who gave me this piece has promised to give me the history of the case". But there is no history, so presumably it was never sent. Also he made the first colour pictures of the pathology in Hodgkin's disease, which Thomas Hodgkin showed when he read his classic paper on the malady in London in $1832 .{ }^{5}$

There is an interesting early example of iron therapy in an attractive painting which shows the face of a young woman with anaemia before and after treatment with ferrous carbonate.

\section{Comments on the paintings}

Although patients with cyanotic heart disease are shown there is no separate delineation of clubbing of the fingers which is perhaps surprising because the sign was known at this time. For example in 1831 James Hope recorded in a cyanotic child aged 11 , that "the last phalanges of the fingers and toes are bulbous ... the finger and toe nails grow very fast requiring to be cut every four or five days". ${ }^{6}$

The specimen (fig 2) of an apparently bicuspid aortic valve (A 532) shows what may be a third commissure which could indicate a rheumatic origin. But, as Lewis and Grant pointed out, the common form of a congenital bicuspid valve is that in which a ridge partially subdivides a cusp, and they showed that it was only by the relation of the annulus to the aortic media that the congenital and acquired forms could be distinguished. ${ }^{7}$ So this specimen may in fact be one of the earliest pictures of congenital calcific aortic stenosis. 
The aortic dissection (A 15) requires further comment. Dr Howard Burchell (personal communication) has pointed out that T R H Laennec, who was the leading clinician in Paris on the occasion of Carswell's first visit, identified and named dissection of the aorta at about that time. So Carswell would very probably have known of the acute lesion, but understandably he may not have recognised, and certainly did not label, his own specimen of the chronic lesion as being a dissection.

\section{The atlas of his water-colour drawings}

By 1831 having completed his work in Paris, Carswell took up his post as professor of pathological anatomy at University College London and started to prepare an atlas of his drawings. The folio volume was published in 1838 with the title Pathological Anatomy. Illustrations of the Elementary Forms of Disease. ${ }^{1}$ It was dedicated to his teacher, Professor James Jeffray, "to express my gratitude, and to acknowledge the influence you thus exercised in directing my attention in a special manner to the study of Pathological Anatomy". It has 44 beautiful coloured plates, each containing several

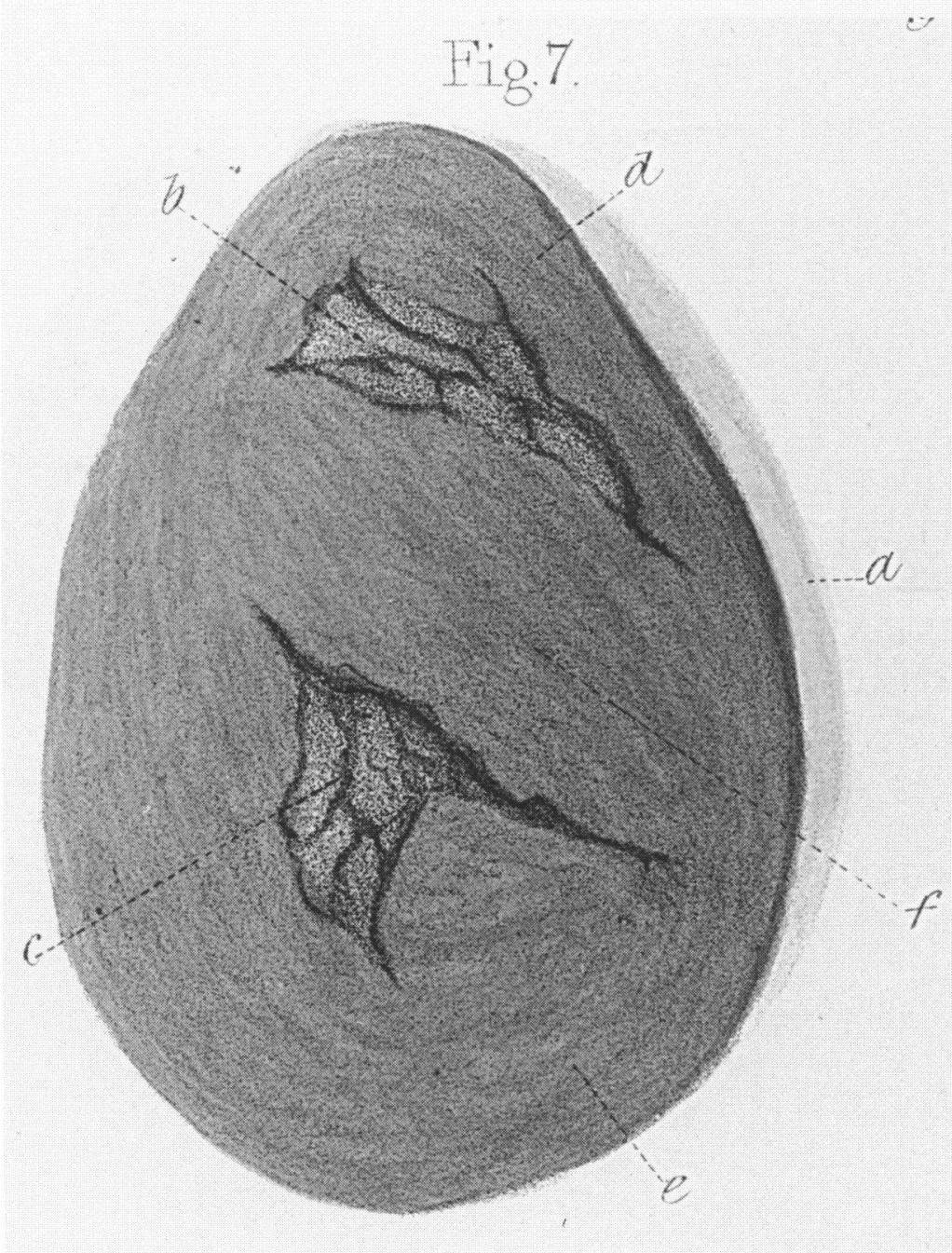

Figure 6 "Congenital cardiac hypertrophy" reproduced from Carswell $R$. Pathological anatomy. Illustrations of the elementary forms of disease. London: Longman Orme Brown Green and Longman, 1838. Hypertrophy, plate IV, figure 7. paintings. He was an expert lithographer who put the illustrations onto stone himself, while the colouring was done under his immediate supervision.

The contents are arranged according to pathological states and not in body systems. There are eleven fasciculi: inflammation, analagous tissues, atrophy, hypertrophy, pus, mortification, haemmorhage, softening, melanoma, carcinoma, and tubercle. Carswell says that there are some subjects such as calculi, entozoa and monstrosities that he proposes to include if a second edition is required-but it never was. The volume was hailed as having "brought this branch of medical science up to the highest point of which it was susceptible". ${ }^{8}$ A few years later Rudolph Virchow founded the study of cellular pathology using the microscope.

The illustrations that caught my eye are figures 6 and 7 of plate II on hypertrophy, described as "A case of congenital concentric hypertrophy of the heart, which occurred in a woman above forty years of age" (fig 6). The transverse section seems to show hypertrophy of both ventricles with a very thick septum and small cavities, and the external view shows a large coronary artery. Was this the first illustration of hypertrophic cardiomyopathy? Sadly, no! On referring to the original drawings (A 531) one finds this same case described as "atrophy of the heart", measuring "from its apex to its basis only two inches and a half and the broadest part two and a quarter inches". Quite what it does represent it is difficult to know. Perhaps it came from a patient with severe and chronic wasting. I mention it in case someone else also gets led astray.

\section{Other atlases of morbid anatomy}

The invention of lithography in 1800 made it much easier to produce illustrated books, and several atlases of pathology were published in the next few decades in Europe and Britain. The one by James Hope $(1801-1841)^{9}$ is of especial interest to us because he made such notable contributions to British cardiology with his identification of left ventricular failure and his experimental work on cardiac murmurs. It comes as a pleasant surprise to find that Hope too was an accomplished artist who produced the original paintings for the coloured lithographs in his book, which was designed "to facilitate the study of morbid anatomy in connexion with symptoms". There are 48 plates containing 260 figures of which 20 illustrate aspects of heart disease.

\section{Carswell's career}

Having taken up his Chair he was appointed physician to the College's associated hospital then named the North London Hospital, later University College Hospital. But poor health and lack of success in private practice led him to resign both appointments in 1840 and to take up the post of physician to the King of the Belgians. He married Mlle Marguerite Chardenot in 1850; they had no children. Queen Victoria made him a Knight to show her appreciation of his services to Louis Phillipe, King of the French, while in exile in England. For the rest of his life Carswell lived 
mostly at Lacken near Brussels where he was greatly respected for his medical services to the poor. He did no further scientific work and died there in 1857 from chronic lung disease.

1 Carswell R. Pathological anatomy. Illustrations of the elementary forms of disease. London: Longman Orme Brown Green and Longman, 1838. 2 Cameron GR. Robert Carswell, pathologist. Univ Coll Hosp
Mag 1951;36:10-1.
3 President's Address. Sir Robert Carswell. Proc Roy Med Chir Soc London 1858;2:52-4.

4 Reckert H. Das unbekannte Werk des Pathologen Robert Carswell (1793-1857). Cologne: Instituts fur Geschichte der Medizin der Universitat zu Koln, 1982.

5 Dawson PJ. The original illustrations of Hodgkin's disease. Arch Intern Med 1968;121:288.

Arch Intern Med 1968;121:288.
6 Hope J. A treatise on the diseases of the heart and great vessels. 1st Hope J. A treatise on the diseases

7 Lewis T, Grant RT. Observations relating to subacute infective endocarditis. Heart 1923;10:21-100.

8 JFP. Sir Robert Carswell. Dict Nat Biog 1887;9:191.

9 Hope J. Principles and illustrations of morbid anatomy. London: Whittaker and Co, 1834. 